\title{
Language Learning Difficulties among Malaysian Gifted Students
}

\author{
Melor Md Yunus ${ }^{1}$, Ainil Sulaiman ${ }^{2}$, Mohd Hasrul Kamarulzaman ${ }^{1} \&$ Noriah Mohd Ishak ${ }^{1}$ \\ ${ }^{1}$ PERMATA Pintar National Gifted Center, National University of Malaysia, Malaysia \\ ${ }^{2}$ Faculty of Education, National University of Malaysia, Malaysia \\ Correspondence: Mohd Hasrul Kamarulzaman, PERMATA Pintar National Gifted Center, National University of \\ Malaysia, 43650 Bangi, Selangor, Malaysia. Tel: 60-13-388-7809; 60-16-328-6534. E-mail: \\ hasrulkamarul@ukm.my
}

Received: March 11, 2013 Accepted: August 30, 2013 Online Published: October 29, 2013

doi:10.5539/ass.v9n15p130 URL: http://dx.doi.org/ass.v9n15p130

\begin{abstract}
Gifted students have unique characteristics and have different ways of thinking and learning. These characteristics affect how they learn a language. This study investigates gifted students' difficulties in English language learning. Data was gathered using semi structured interview with six gifted students of PERMATA Pintar National Gifted Centre. In this study, interview analysis was used to analyze interview transcripts in order to find gifted language learning difficulties among gifted students. An analysis of responses was done by identifying similarities among six gifted students in terms of area of difficulties, language skills difficulties and also reasons behind their problems. Findings revealed that the common difficulties in English language learning faced by gifted students were related to speaking in English, grammar and lack of vocabulary. Furthermore, all gifted students interviewed perceived that speaking skill is the hardest skill to learn. Such insight into English language learning difficulties is helpful to teachers and educators as it provides useful information for teaching and learning the target language as well as developing the suitable education environment for gifted students to reach their potential in language learning.
\end{abstract}

Keywords: gifted students, English language learning difficulties

\section{Introduction}

Malaysia is committed to develop an educational system for all students where equity and excellence are the main aim of the education process (Noriah, Rosadah \& Rahayah, 2009). Equity here refers to the opportunities and support for every student to receive a good education while excellence refers to the development of their learning potential to the highest level of attainment possible for each and every student. The diversity of students, considering that the progress of physical, emotional, and cognitive development of different groups of learners happen at different pace, intensify the barriers for providing appropriate instruction and environment that cater the student needs, especially with the case of gifted students.

Moreover, in the state of education, the needs of gifted students might be neglected unless awareness on the way they learn and think are taken into consideration. Therefore, educators need to be aware of the differences on gifted students in order to provide the best and accountable ways of learning and teaching. On top of that, educators must also become aware and thus find ways to overcome the challenges in differentiating effectively for gifted students. Failing to find the appropriate ways to overcome these barriers might lead to declining level of achievement among gifted students (Sanders \& Horn, 1998; Stambaugh, 2001).

English is the second language in Malaysia, considered one of the most widely used language in the region. The importance of English language as the world's language has always contributed to the learning and use of English to gain information in science and technology. In order to access insurmountable data of information and to succeed in all fields, Malaysia has placed the importance of English literacy and competence as a priority. However, recently, there has been an alarming concern over the standard of English proficiency among Malaysian students that is worrisome (Saadiyah \& Kaladevi, 2009).

Gifted students have unique characteristics and have different ways of thinking and learning. These characteristics affect how they learn a language. It also influences the way they overcome problems in language learning and improve their language performance. However, the characteristics cannot be generalized to all students identified as gifted students because each student has his/her own unique patterns of development 
(Clark, 2002). According to Tretter (2010), certain learning strategies and skills are especially effective for enhancing gifted students' learning. Therefore, this study attempts to investigate English language learning difficulties face by gifted students enrolled in the special programme called PERMATA Pintar Education Programme. The programme identified gifted students who have higher ability in mathematics and science domains only. It did not look at students' language ability in identification process of gifted students. Thus, the students' language skills are remained unknown, particularly in the learning of second language. On top of that, all teaching and learning in this special programme are conducted English language. However, due to students' level of English proficiency, Malay language is use alongside with English. This indicated that PERMATA Pintar gifted students might face difficulties in the use English language. In addition, these students have special learning needs, which if not met, can lead to frustration, a loss of self-esteem, boredom, laziness and underachievement (Crocker, 2004). More information is needed to define the language learning difficulties faced by gifted students in order to develop the suitable education environment and material for gifted students to reach their potential in language learning.

\section{Literature Review}

\subsection{PERMATA Pintar Education Programme}

PERMATA Pintar Education Programme is the first educational programme that jewels gifted students in Malaysia. Universiti Kebangsaan Malaysia (UKM) has been entrusted by the Prime Minister to implement this educational programme through PERMATA Pintar National Gifted Centre. The programme was formed in January 2010 and was commenced in January 17, 2011. The first intake of gifted students for this programme is a total of 114 students aged 16 years old form all over Malaysia who has been through three of screening tests: PERMATA Pintar UKM1, test and test competency UKM2 PERMATA Pintar Mathematics and Science (test UKM3).

The objective of the programme is to produce gifted students who have the following characteristics; competent, skilled and competitive to achieve greatness in academic at national and international level, has good values, high creativity in generating solutions to problem, innovative and critical thinking, exhibit good leadership, responsible, good language skills and can communicate effectively and demonstrate sensitivity towards social responsibility.

PERMATA Pintar Education Programme focuses on holistic education and learning based on the Philosophy of Education. It also emphasizes the development of physical, emotional, spiritual, intellectual and social balance. Moreover, the programme is a full-time program that takes about two years. It emphasizes on learning differentiation (differentiated learning) in which all students learn at different levels according to their learning level. It also emphasizes student-centred learning and using various methods including cooperative learning and collaborative methods based, lecture, large group and small groups in laboratory and field studies, research projects with research expert group UKM, research reports, construction folio, mobility programs and student exchanges, self-esteem building activities modular and spiritual programs and problem-based learning (PBL). Students are introduced to the concept of Higher Order Thinking (HOT) to help them develop creative thinking, critical and innovative in their learning. All learning are conducted in both languages; using Bahasa Malaysia (Malay language) and English. Hence, competency in both languages is crucial.

\subsection{Characteristics of Gifted Students}

The gifted students have exceptional characteristics that differentiate them from their peers. According to Gagnê (1995), gifted individuals demonstrate outstanding levels of aptitude (defined as an exceptional ability to reason and learn) or competence (documented performance or achievement) in one or more domains. Clark (2002) summarized the list of characteristics of academically gifted which were divided into different categories including; cognitive characteristics (e.g. retention of large quantities of information, advance comprehension, varied interest, high curiosity, high level of language development and verbal ability), affective characteristics (e.g. unusual sensitivity towards others feelings, keen sense of humor), physical characteristics, intuitive characteristics (open to intuitive experiences and creativity apparent in all areas), and societal characteristics (strongly motivated by self- actualization needs, advances capacity for conceptualizing and solving societal problems, leadership and involvement with the meta-needs of society).

In addition, research by Renzulli (2005) identified characteristics such as the ability to learn more rapidly than other students, understanding of complex or abstract topics, and advanced verbal ability and problem-solving skills (cited in Reis \& Sullivan, 2009). Moreover, Touron et al. (2005) stated that gifted students are different from their normal peers in many developmental aspects such as physical and psychomotor, emotional, spiritual, intellectual and social. 
Besides that, local researcher Aliza and Hamidah (2009) also provided some of the general characteristics of gifted, talented and more able learners. They stated that gifted, talented and more able learners might display the variety of attributes such as like to read materials that are considered difficult for their age, show great interest towards science and literature, show ability to solve complex problems, exhibit a strong sense of curiosity, be very articulate with their ideas, possess emotional stability and are very friendly or polite, possess entrepreneurial spirit, have a strong sense of discipline or self-control, be very creative in producing innovative ideas, show a great understanding towards an event they encounter, show ingenuity in expressions through speech and writing, demonstrate a willingness to accept complexity, have an ability to work things out in their head very quickly, have a good memory that they can access easily, be very adaptable, learn new topic areas very quickly, effortlessly and score good grades for most subjects, exhibit and apply common sense in many situations, use a great amount of vocabulary in their speech and writing, like to ask a lot of questions, display high concentration levels, show obsession towards an interest area, show a strong sense of leadership, show consistency and commitment to a cause, possess great confidence and character, and be very energetic most of the time.

\subsection{Language Difficulties Faced by Malaysian ESL Learners}

Since English is not the first language of many students in Malaysia, students might encounter some difficulties when learning the language. Marlyna, Tan and Khazriyati's (2007) study on interference effect of Bahasa Malaysia in the acquisition of English literacy among Form One students revealed that students have difficulties in using correct English grammar in their writing, and made errors such as wrong use of articles and subject-verb agreement. The study claimed that a large number of errors identified suggest interference of Malay grammar. Similarly, Neda, Mariaan and Seyyed (2012) findings showed tangible first language interference in students' writing. Her study also revealed that Malaysian ESL learners have problems in writing tasks, especially in language use (grammar) and punctuation.

In addition, many studies have been done with the concern over low literacy attainment in English language among Malaysian learners. Normazidah, Lie and Hazita (2012) presented a review of recent research that investigates the problem and the practice of English language teaching and learning in Malaysia. It also aimed to identify the factors that contribute to low or limited English literacy achievement among Malaysian learners. Two important issues regarding English language learning in Malaysia were summarized in the paper. Firstly, Bahasa Malaysia has a strong influence over the learning of English. Interference of mother tongue language system in some ways contributes to wrong use of English grammatical rules, morphology and syntax. Second, a strong emphasis is given on the teaching of reading and writing skills and the mastering of grammatical rules. Her research also stated that common classroom practices suggest that the teaching of English literacy neglects the sociocultural elements of language learning. English language learning is presented as learning a set of language mechanics with 'fixed' ways of using the language; isolated from its communicative use. In brief, all ESL students face more complicated problems, which may be either cultural or linguistic ones.

\section{Methodology}

This study employed a qualitative method to investigate gifted students' difficulties in language learning. Semi structured interview was conducted on six gifted students to gain insight into gifted students' use of LLS and their difficulties when learning English. The interviews were done based on the administration procedures set by the researcher. According to Bryman (2004), semi structured interview refers to a context in which the interviewer has a series of questions that are $\mathrm{n}$ general of an interview schedule but is able to vary the sequence of questions. Therefore, semi structured interview was selected because it is more flexible as the questions asked are frequently somewhat more general and the interviewer usually has some latitude to ask further questions based on response. Semi structure interview involves the preparation of an interview guide that lists a predetermined set of questions or issues that are to be explored during the interview. It serves as a checklist during the interview and provides a more systematic and comprehensive way to obtain the same basic lines of inquiry with each person interviewed.

\subsection{Data Collection Procedure}

The interviews were done face to face and were conducted in English. However, students were given a choice to use either Bahasa Malaysia or English or both to answer the questions. The choice was given to reduce students' anxiety and making sure that they are able to answer all of the questions honestly and smoothly without any problems regarding language barrier. The samples were voluntarily chosen by the instructor consisted of two male and four females students. The drawback of this approach is the respondents might not be heterogeneous and thus not representing the population. The researcher conducted the interview based on the interview protocol. 
Issues of informed consent and confidentiality were appropriately addresses in the course of interview (Boyce \& Neale, 2006). The interviews were conducted in 26 April 2012. Before each interview, the respondent was briefed on the purpose of the study and topic to be discussed in general and also a few technical aspects of an interview such as turn taking and clarity of voice (Norhayati, 2006). The entire interview was tape-recorded. During the interview, the researcher re-confirmed permission to record, confidentiality and transcript were provided. The researcher jotted down important information during the interview. The allocated time for each interview was 10 minutes.

After each session, the researcher listened to the tape and transcribed each dialogue. Alteration was made to elicit only useful information and extracted some redundant information based on the purpose and research questions of the study. The responses obtained from the interviewee were translated to English and relevant responses were coded to ease the process of transcription. In addition, to ensure the originality, the researcher listens to the tape a few times and double-checks the transcription.

Table 1. Background information of students interviewed

\begin{tabular}{lll}
\hline & Cognitive Style & Language Proficiency/Result \\
\hline Female Student (Siti) & Field Dependent Learner & Medium Proficiency (C+) \\
Male Student (Abu) & Field Independent Learner & High Proficiency (A-) \\
Male Student (Ali) & Field Independent Learner & Medium Proficiency (C+) \\
Female Student (Ayu) & Field Dependent Learner & Medium Proficiency (C) \\
Female Student (Ami) & Field Dependent Learner & Medium Proficiency (C) \\
Female Student (Nurul) & Field Independent Learner & Medium Proficiency (B) \\
\hline
\end{tabular}

Table 1 provides background of six gifted students who participated in qualitative data collection. Pseudonyms were used to ease the process of analysis and at the same time preserve anonymous of the interviewee. The cognitive styles of the students were determined based on students' score for Group Embedded Figure Test (GEFT) while language proficiency was based on their mock TOEFL result. Total of three students were categorized into field independent and field dependent respectively. Meanwhile, only one student was at high proficiency level and the rest were at medium proficiency level. The questions and analysis from the interview looked at some difficulties the students faced regarding language learning and the ways they overcome those difficulties. Each interview session was recorded and transcribed.

\subsection{Data Analysis}

For this study, interview analysis was used to analyze interview transcripts in order to investigate gifted students' use of language learning strategies in detail and their difficulties in language learning. According to Hsieh and Shannon (2005, p. 1278), qualitative analysis can be defined as a "research method for the subjective interpretation of the content of text data through the systematic classification process of coding and identifying themes or patterns".

The analysis of responses in order to find gifted students' difficulties in language learning was done by identifying similarities among six gifted students in terms of area of difficulties, language skills difficulties and also reasons behind their problems. To ease the process of assigning each coded response, the categories, should be defined in a way that they are internally as homogeneous as possible and externally as heterogeneous as possible (Lincoln \& Guba, 1985).

\section{Results and Findings}

Since English is not the first language of many students in Malaysia, students might encounter some difficulties when learning the language. In this case, gifted students demonstrate outstanding levels of aptitude or competence in certain domain (Gagne, 1995). However, in language wise, their performance and competency are at par with their peers. Their exceptional characteristics might influence their way of thinking and learning a language. Therefore, the gifted students might face some difficulties when learning English as a second language. To find out more, the semi-structured interview was conducted which focused on gifted students' difficulties in language learning in general.

When the students were asked about problems that they have when learning English based on their personel 
experience, their answers were to some extent similar to each other regardless proficiency and cognitive styles. Gifted students normally are aware of their own difficulties and weaknesses. The high use of metacognitive strategies was reflected as they enable to identify errors in understanding or producing the new language. The findings from interviews done on six gifted students illustrated that among the common difficulties in language learning faced by gifted students were related to speaking in English, grammar and lack of vocabulary. An example of the student answer was, "Usually, something related to grammar like past tense and things like that. I'm not sure when and how to use it. And also I don't have strong vocabulary."

From this, it can be interpreted that students faced difficulty in applying grammatical rules in discourse manner. This is common problem among Malaysian students. This could be supported by study of Saadiyah and Kaladevi (2009) in their research on error analysis of the written English essay of form four students, which revealed that students generally have problem in using correct grammatical rules in writing. Some of the common errors are wrong application of verb tense, inappropriate word choice and prepositions.

To find more on language use of the students, the related question asked to all the students was "What are the languages you usually use at home and with your friends here (at the Centre)?" The purpose of this question was to find out what are the languages students most comfortable using and familiar with. All of students chose their first language that is Malay language and only one student (Abu) mentioned that he used Javanese language at home because of his family origin. Half of the students stated that they sometimes use English to communicate with their friends or family. Lim (1994) in her study on fluency and accuracy in spoken English concluded that the use of mother tongue in peer interaction were among the possible causes of low spoken English proficiency. Malay language-as the national language of Malaysia and also a language of medium instruction in Malaysian schools-has a strong influence over the learning of English (Normazidah, Lie \& Hazita, 2012). In addition, according to Nor Hashimah Jalaludin, Norsimah and Kesumawati (2008), one of the main factors affecting students' inability to successfully acquire English literacy are linguistic differences particularly in the aspect of morphology and syntax between the Malay language and English. These possible factors presented by past studies indicate that first language might influence students' competency in second language.

On top of that, all of the students interviewed mentioned that they seldom use English when talking to their friends. They will try to speak English in the formal context such as when the teacher asks them questions in English. Abu gave his opinion based on his past experience regarding this "My teacher from my former school is very strict. She scared me and made me talk to her in English. Thus, in a year, there is an improvement in my speaking skill. I think if the school provides an English language speaking environment, it might work". He believes that by enforcing English-speaking environment in school, it will shed a light on students' confidence in speaking and therefore enhance their speaking skill.

Furthermore, among the four language skills; writing, reading, listening, speaking, the finding indicated that all gifted students interviewed perceived that speaking skill is the hardest skill to learn. Ali said that he seldom use English when communicating with family and friends and might be the reason why he perceived speaking English as the hardest skill to master. Four students (Abu, Ayu, Ami \& Nurul) stated that they are afraid to speak English with their friends or family. They worried about making grammatical mistakes and not having enough confidence to use the language. This might be due to cautious of negative physical response, such as laughing at them, that they might receive when they make mistake or speak English incorrectly. Unfamiliarity with some of English vocabulary affects their ability to speak English fluently according to Ayu and Nurul. This caused them to code switch or use their mother tongue to ensure their meaning, intentions or thought.

According to Fauziah and Nita (2002), factors such limited opportunities to use English outside the classroom (external factor), negative attitude towards English (internal factor) and lack of confidence (internal factor) were some of the reasons for students' low proficiency in English from teacher perspective. As a result, students usually experience moderate anxiety and are reluctant to speak in English for fear of being judge negatively (Hiew, 2012). This might be the reason why gifted students afraid to speak English. However, having moderate level of anxiety in second language learning could help students to build desire to learn, to motivate, and enhance their effort to do better (Hadley, 1992).

In addition, gifted students portrayed good affords by willing to practice their English if they are given opportunity to speak with friends or speaker of English. They also demonstrated positive perception towards learning English. "Positive emotion and attitudes towards the target language can make language learning far more effective and fun" (Hurd, 2008, p. 218). Furthermore, some of the students perceived learning English as "easy" and "not hard". Nurul in her interview said that English classes are laid back and not very difficult. This similar with findings from Rosadah, Zalizan and Noriah (2009) which concluded that academically talented 
students will regard learning as easy if the students successfully associate their positive attitudes with their learning.

From the gifted students' point of view, listening skill is considered the second hardest skill to learn by three students (Siti, Ayu \& Nurul). Moreover, some of the problems in listening skill encounter by the students were mainly related to native speaker accent, fast rate speech and pronunciation. Moreover, one student (Abu) stated that one of his challenges in language learning is the teacher's style of teaching. Abu who is a field independent learner might prefer more autonomy and less personel interaction when learning English feel that sometimes the teacher's way of teaching is not suitable with the subject matters teaching. His answer was "Sometimes the teacher. The way he/she teaches is not suitable. Sometimes it's regarding the subject matters, or the way he/she teaches is not suitable".

The differentiated learning concept that is integrated in PERMATA Pintar Educational Programme take gifted students' level of attainment in each domain into consideration in order to provide productive and effective learning environment that can stretch gifted students capability and potential in every domain. For example, different tasks are given to different level of learner in a same class. Despite that, classes are composed of students who have different style preferences. Hence, teaching style and student's learning preference might contradict and it is the role of the teacher to aware and adopt flexible approach to their instructional practice so that their ultimate approach is integrated (Pithers, 2001).

Furthermore, to get to know students' opinion on language learning in general, the researcher asked the students to describe how they learn in general and in language learning. In addition, Rosadah, Noriah and Melor (2009) in her study found that academically talented students are interested in learning to become independent learners. This can be seen in some of the students' responses in the interview. For example, when the researcher asked about how Siti learn in general and in language learning, her answer was "In general, if something is very difficult, I'm dependent because I need more guidance. If something that we can understand it on our own, like history or religion subjects, we can read it. Do not need to refer to someone that much. As for English, sometimes it can be (self-study), sometimes not due to confusion". This shows that she prefers independent learning for English language as did not require much guidance in language learning compare for other subjects. In addition, three of the students interviewed (Abu, Ami \& Nurul) said they would find answer by themselves first before asking a friend when they do not the meaning of new English words. This shows that the students are independent and practise self-discovery in learning.

The six gifted students interviewed show a strong desire to be better in English and put more effort and practice to overcome their difficulties. However, three out of six students (Siti, Ali \& Ayu) said that they practice their writing more than speaking, such as referring to past year questions, read dictionaries in order to improve their English competency. All of the students also used dictionary as their main sources. Although gifted students are exposed to the new way of teaching and learning under PERMATA Pintar Education Programme, they still caught up with the exam oriented system that place focus on mastering and rote learning skills to apply in examination. Unfortunately, the use of conventional strategies such as past year examination questions, works sheet and exercise book still common among the students.

From the analysis of the interview, it can be concluded that gifted students' difficulties were more on communicative and productive skills. Problems are prone to communicative aspect and underutilized speaking strategies. However, gifted students are aware of their own difficulties and show positive attitudes on language learning. They have good devices, such as ability and potential, for language learning and they just need to know how to fully utilize those devices.

\section{Discussion}

As mentioned before, PERMATA Pintar gifted students were identified as gifted based on their ability in cognitive domain such as Mathematics and Science subjects. This domain is focus on numerical aspect. However, language on the other hand is not. The findings of the study revealed that PERMATA Pintar gifted students have common problems in language learning such as difficulties in speaking in English, use of appropriate grammar and lack of vocabulary. These problems affected the students' performance in language. Therefore, teachers, school professionals and administration of PERMATA Pintar National Gifted Centre should take immediate actions such as providing incentive programme and support to address these problems. Differentiated instruction is proposed as a suitable approach of teaching the gifted learners where adjustment are made to the content, learning process, affective aspects and learning environment to cater to the level of student preparedness, interests and learning background.

In addition, the educators especially teachers and school administration should be aware of these individual 
differences among form four PERMATA Pintar gifted students. It is appropriate for school professionals to utilize a variety of instructional strategies to accommodate the needs of PERMATA Pintar gifted students such as emphasizing more on communicative aspect of language by giving more interaction chances, participation in role plays and stimulation. Moreover, students should be taught how to coordinate their language learning strategies used based on their cognitive styles and level of language proficiency in order for them to actively and effectively learn the language.

In conclusion, the findings of the study can be used as guidelines to develop appropriate strategy and approach coupled with rigorous intellectual support from the teachers, school professional of PERMATA Pintar National Gifted Centre and the Ministry of Education to provide worthwhile educational experiences for gifted students in the aspect of language learning. It is important to cater and provide the best environment in education for gifted students because they have tremendous potential to be developed into highly valuable resource capital for the future wellbeing of this country.

The current study represents the first investigation of gifted students under a special programme in an ESL context in Malaysia. Further studies are needed to explore gifted students' use, not only ESL context, but also EFL context. In addition, comparative study need to be conducted to observe if there are any differences existing in between gifted students from the programme and academically talented students from boarding school such as MRSM in terms of language learning strategy use among successful learners.

\section{Conclusion}

The findings from interviews done on six PERMATA Pintar gifted students illustrated that among the common difficulties in language learning faced by gifted students were related to speaking in English, grammar and lack of vocabulary. Furthermore, among the four language skills; writing, reading, listening, speaking, the finding indicated that all gifted students interviewed perceived that speaking skill is the hardest skill to learn. Cautious about making grammatical mistakes, not having enough confidence, and lack of vocabulary are among the factors affecting their ability to speak English fluently. Moreover, listening skill is considered the second hardest skill to learn by half of the students interviewed. Some of the problems in listening skill encounter by the students were mainly related to native speaker accent, fast rate speech and pronunciation. From the analysis of the interview, it can be concluded that gifted students' difficulties were more on communicative and productive skills. Besides that, PERMATA Pintar gifted students employed conventional strategies such as using dictionary and do exercises to overcome their language weaknesses. However, PERMATA Pintar gifted students are aware of their own difficulties and show positive attitudes on language learning. This is accordance with gifted students portrayal a good effort by willing to practice their English of they are given opportunity to speak with friends or speaker of English.

\section{References}

Alias, A., \& Yamat, H. (2009). Ciri Kanak-Kanak Pintar Cerdas. In M. I. Noriah, A. M. Rosadah \& M. Y. S. Fatimah (Eds.), PERMATA Pintar: Pengalaman UKM. Pusat PERMATA Pintar Negara, Universiti Kebangsaan Malaysia.

Boyce, C., \& Neale, P. (2006). Conducting In-Depth Interviews: A Guide for Designing and Conducting In-Depth Interviews for Evaluation Input. Pathfinder International Tool Series. Retrieved July 11, 2012, from

http://www.esfagentschap.be/uploadedfiles/voor_esf_promotoren/zelfevaluatieesfproject/m_e_tool_series_i ndepth_interviews.pdf

Byrman, A. (2004). Social Research Methods (2nd ed.). Oxford University Press Inc., New York.

Clark, B. (2002). Growing Up Gifted. Upper Sadle River, NJ: Merrill Prentice Hall.

Crocker, T. (2004). Underachievement: Is our vision too narrowed and blinkered? Fools step in where angels fear to tread. Gifted, 131, 10-14.

Darus, S., \& Subramaniam, K. (2009). Error Analysis of the Written English Essay of Secondary School Students in Malaysia: A Case Study. European Journal of Social Sciences, 8(3), 483-495.

Fauziah, H., \& Nita, F. S. (2002). Why aren't Students Proficient in ESL: The Teachers' Perspective. The English Teacher. Retrieved from http://www.melta.org.my/ET/2002/wp10.html

Gagné, F. (1995). From giftedness to talent: A developmental model and its impact on the language of the field. Roeper Review, 18(2), 103-111. http://dx.doi.org/10.1080/02783199509553709

Ghabool, N., Edwina, M., \& Hossein, S. (2012). Investigating Malaysian ESL Students' Writing Problems on 
Conventions, Punctuation, and Language Use at Secondary School Level. Journal of Studies in Education, 2(3). http://dx.doi.org/10.5296/jse.v2i3.1892

Hadley, O. A. (1992). Teaching Language in Context. Heinle and Heinle, Boston.

Hiew, W. (2012). English Language Teaching And Learning Issues In Malaysia: Learners' Perceptions Via Facebook Dialogue. Journal of Arts, Science and Commerce, 3(1).

Hsieh, H. F., \& Shannon, S. E. (2005). Three approaches to qualitative content analysis. Qualitative Health Research, 15(9), 1277-1288. http://dx.doi.org/10.1177/1049732305276687

Hurd, S. (2008). Affect and strategy use in independent language learning. In S. Hurd \& T. Lewis (Eds.), Language learning strategies in independent setting. Multilingual Matters.

Jalaludin, N. H., Awal, N. M., \& Bakar, K. A. (2008). The mastery of English language among lower secondary school students in Malaysia: A linguistic analysis. European Journal of Social Sciences, 7(2), 106-119.

Leedy, P., \& Ormrod, J. (2001). Practical research: Planning and design (7th ed.). Upper Saddle River, NJ: Merrill Prentice Hall. Thousand Oaks: SAGE Publications.

Lim, S. L. (1994). Fluency and accuracy in spoken English-implications for classroom practice in a bilingual context. The English Teacher, 23, 1-7.

Lincoln, Y. S., \& Guba, E. G. (1985). Naturalistic Inquiry. Beverly Hills, CA: Sage Publications nor Hashimah Jalaludin, Norsimah Mat Awal and Kesumawati Abu Bakar. 2008. The mastery of English language among lower secondary school students in Malaysia: A linguistic analysis. European Journal of Social Sciences, 7(2), 106-119.

Maros, M., Hua, T. K., \& Salehuddin, K. (2007). Interference in learning English: Grammatical errors in English essay writing among rural Malay secondary school students in Malaysia. Journal e-Bangi, 2(2), 1-15.

Noriah, M. I., Rosadah, A. M., \& Rahayah, A. S. (2009). Sejarah dan Konsep PERMATA Pintar. In M. I. Noriah, A. M. Rosadah \& M. Y. S. Fatimah (Eds.), PERMATA Pintar: Pengalaman UKM (pp. 131-144). Pusat PERMATA Pintar Negara, Universiti Kebangsaan Malaysia.

Normazidah, Lie, K. W., \& Azman, H. (2012). Exploring English Language Learning And. Teaching in Malaysia. GEMA Online, 12(1). Retrieved from http://journalarticle.ukm.my/3262/1/pp_35_51.pdf

Pithers, B. (2001). An Aspect of Vocational Teachers' Cognitive Style: Field Dependence-Field Independence. Australian and New Zealand Journal of Vocational Education Research, 9(2), 47-60.

Reis, S. M., \& Sullivan, E. E. (2009). Characteristics of Gifted Learners: Consistently Varied; Refreshingly Diverse. In F. A. Karnes \& S. M. Bean (Eds.), Method and Material for Teaching the Gifted (3rd ed.). Prufrock Press Inc.

Rizal, J. (2005). Language Learning Strategy among EFL learners in private college in Indonesia. Master Thesis. Universiti Kebangsaan Malaysia.

Rosadah, A. M., Noriah, M. I., \& Melor, M. Y. (2009). Kepintaran dan Pintar Cerdas Berbakat: Definisi dan Makna. In M. I. D. Noriah, A. M. Rosadah \& M. Y. S. Fatimah (Eds.), PERMATA Pintar: Pengalaman UKM (pp. 131-144). Pusat PERMATA Pintar Negara, Universiti Kebangsaan Malaysia.

Samad, N. (2006). Language learning strategies use of large class. Master Thesis. Universiti Kebangsaan Malaysia.

Sanders, W. L., \& Horn, S. P. (1998). Research findings from the Tennessee Value-Added Assessment System (TVAAS) database: Implications for educational evaluation and research. Journal of Personnel Evaluations in Education, 12(3), 247-256. http://dx.doi.org/10.1023/A:1008067210518

Stambaugh, T. (2001). Cluster grouping the gifted: One school's journey. The Review: Ohio Association for Gifted Children, 4-5.

\section{Copyrights}

Copyright for this article is retained by the author(s), with first publication rights granted to the journal.

This is an open-access article distributed under the terms and conditions of the Creative Commons Attribution license (http://creativecommons.org/licenses/by/3.0/). 